\title{
ANALISIS PENGENDALIAN KUALITAS UNTUK MEMINIMASI PRODUK CACAT PADA BAYAM JEPANG
}

\section{QUALITY CONTROL ANALYSIS TO MINIMIZE DEFECTIVE PRODUCTS IN THE JAPANESE SPINACH}

\author{
Tio Katana Diana Br Keliat ${ }^{1)}$ dan Hendrik Johannes Nadapdap ${ }^{1)}$ \\ ${ }^{1)}$ Prodi Agribisnis, Fakultas Pertanian dan Bisnis, Universitas Kristen Satya Wacana \\ Email: 522016094@ student.uksw.edu
}

\begin{abstract}
ABSTRAK
Bayam Jepang adalah komoditas unggulan yang diproduksi oleh PO. Sayur Organik Merbabu dengan tingkat penjualan tertinggi mencapai 1018 kg/bulan. Salah satu faktor yang perlu diperhatikan dalam proses produksi adalah kualitas produk, karena akan berdampak terhadap kepuasan konsumen. Akan tetapi terdapat kendala dalam proses produksi, yaitu sifat tanaman yang sangat rentan rusak dan patah jika tidak diperlakukan secara tepat. Sehingga perlu dilakukan analisis kualitas terhadap Bayam Jepang untuk menekan tingkat kerusakan. Tujuan penelitian ini adalah mengetahui jenis cacat dan faktor-faktor yang mempengaruhi kualitas Bayam Jepang. Penelitian ini dilakukan pada 16 Januari sampai 20 Februari 2020 dengan metode deskripstif kualitatif dan menggunakan alat pengendalian mutu seperti lembar periksa, histogram, peta kendali, pareto dan fishbone. Jumlah informan yang digunakan terdiri dari pemilik usaha, tenaga kerja, petani mitra dan distributor. Setelah dilakukan penelitian ditemukan lima jenis cacat yaitu daun cacat, batang patah, daun kuning, tanaman kerdil dan busuk batang atau daun. Persentase cacat yang paling tinggi adalah daun cacat. Faktor-faktor yang mempengaruhi kualitas Bayam Jepang adalah faktor manusia, metode, dan lingkungan yang didukung dengan pembuatan diagram fishbone.
\end{abstract}

Kata Kunci: Bayam Jepang; faktor-Faktor; jenis cacat; kualitas

\section{ABSTRACT}

Japanese spinach is a superior commodity produced by PO. Sayur Organik Merbabu with the highest level of sales reach $1018 \mathrm{~kg} /$ month. One factor that needs to be considered in production process is product quality, because it will have an impact on customer satisfaction. However, there are obstacles in the production process, namely the nature of plants that are very susceptible to damage and broken if not treated properly. So it is necessary to conduct a quality analysis of Japanese spinach on an ongoing basis to reduce the level of damage. The purpose of this study is to determine the types of defects and factors that affect the quality of Japanese spinach. This research was conducted on January 16 to February 20, 2020 with qualitative descriptive methods and using quality control tools such as check sheets, histograms, control maps, pareto and fishbone. The number of informants used 
consisted of business owners, workers, partner farmers and distributors. After doing the research, five types of defects were found, namely defective leaves, broken stems, yellow leaves, dwarf plants and stems or leaf rot, with the highest percentage of defects being defective leaves. While the factors that influence the quality of Japanese spinach are found, namely human factors, methods, and the environment supported by making fishbone diagrams.

Keywords: factors; Japanese Spinach; quality; type of defect

\section{PENDAHULUAN}

Di Indonesia sistem budidaya semakin mengalami peningkatan dan mulai beralih ke sistem pertanian organik, sistem yang meningkatkan kesehatan agroekosistem, keragaman hayati, siklus biologi dan juga aktivitas biologi tanah (Dermiyati, 2015). Salah satu tanaman yang dibudidayakan dengan sistem organik adalah Bayam Jepang. Menurut Ekaningtias (2011) Bayam Jepang adalah jenis tanaman yang memiliki kandungan vitamin $\mathrm{K}$, A, C, B1, B2, B6, asam folat dan Vitamin E yang baik bagi kesehatan.

Perusahaan PO. Sayur Organik Merbabu atau SOM adalah salah satu perusahaan perseorangan yang berdiri di bidang tanaman hortikultura dan memproduksi Bayam Jepang dengan sistem pertanian organik. Bayam Jepang adalah jenis sayuran yang memiliki tingkat penjualan tertinggi mencapai $1018 \mathrm{~kg} / \mathrm{bulan}$ pada tahun 2019. Dalam proses produksi Bayam Jepang, kualitas adalah faktor penting, karena berdampak terhadap persaingan dan kepuasan konsumen. Salah satu kendala yang ditemukan dalam proses produksi Bayam Jepang adalah sifat tanaman yang sangat rentan kerusakan dan patah, sehingga dapat menurunkan kualitas produk yang akan dipasarkan. Oleh karena itu perlu dilakukan proses pengendalian mutu untuk menekan kerusakan atau cacat pada Bayam Jepang. Pengendalian mutu adalah proses yang digunakan untuk menjamin tingkat kualitas dalam produk atau jasa, yang dilakukan dengan membandingkannya dengan spesifikasi atau standart yang telah ditetapkan (Ratnadi \& Suprianto, 2016).

Proses produksi Bayam Jepang di PO. Sayur Organik Merbabu tidak 
lepas dengan kegiatan pengendalian kualitas, karena PO. Sayur Organik Merbabu telah menerapkan sistem grading untuk produk yang akan dipasarkan. Berdasarkan hasil penelitian Primawati (2017) mengenai pengendalian mutu bayam hijau di CV. Agromart Kabupaten Sleman, pengendalian mutu perlu dilakukan terhadap tenaga kerja, bahan baku, proses budidaya dan lingkungan dengan cara memantau setiap proses, bahan baku dan lingkungan. Hasil penelitian tersebut menunjukkan bahwa faktor tenaga kerja, bahan baku dan lingkungan berpengaruh terhadap kualitas. Pengendalian yang tepat dapat mengurangi kerusakan atau cacat suatu produk.

Berdasarkan latar belakang tersebut perlu dilakukan penelitian mengenai analisis pengendalian kualitas Bayam Jepang untuk mengetahui jenis cacat dan faktor faktor yang mempengaruhi kualitas. Sehingga dapat dilakukan tindakan pencegahan untuk mengurangi kerusakan pada proses produksi Bayam Jepang.

\section{METODE PENELITIAN}

Penelitian dilaksanakan pada bulan Januari hingga Februari 2020 di PO. Sayur Organik Merbabu, Kopeng, Jawa Tengah. Pemilihan tempat dilakukan secara purposive dengan pertimbangan bahwa PO. Sayur Organik Merbabu adalah salah satu perusahaan yang bergerak di bidang pertanian hortikultura dan memproduksi bayam jepang. Metode penelitian yang digunakan adalah deskriptif kualitatif, yaitu jenis penelitian yang berpangkal dari pola pikir yang didasarkan pengamatan terhadap suatu objek atau gejala (Suyitno, 2018). Selain itu penelitian juga menggunakan alat pengendalian mutu yaitu lembar periksa, histogram, pareto, peta kendali dan fishbone yang disajikan dalam tabel dan diagram.

Jenis data yang digunakan adalah data primer dan sekunder. Menurut Sugiono (2009), data primer adalah suatu data yang dapatkan dari lapangan secara langsung. Sedangkan data sekunder adalah data yang didapatkan dari buku, jurnal, instansi, balai penelitian, dan dinas yang terkait dengan penelitian. Informan yang 
digunakan adalah 4 orang yaitu pemilik usaha sebagai Key Informant dan petani mitra, tenaga kerja, distributor sebagai informan tambahan. Menurut Suyitno (2018) pengambilan data menggunakan metode kualitatif yang bersifat tentatif karena ditentukan permasalahan dan data. Data dikumpulkan dengan teknik survei, wawancara, dan studi dokumentasi.

Menurut Nugrahani (2014) analisis data yang digunakan dalam kualitatif adalah sebagai berikut:

1. Reduksi Data

Pemilihan, seleksi, pemfokusan, penyederhanaan dari infromasi yang didapatan untuk mendukung data penelitian.

2. Sajian Data

Sekumpulan informasi yang dijadikan dasar untuk menarik kesimpulan dan juga suatu tindakan selanjutnya.

3. Penarikan Simpulan

Kegiatan penafsiran data melalui data dilapangan dan juga data yang telah dinterpretasi.

Selain analisis di atas, penelitian ini menggunakan alat pengendalian kualitas yang disajikan secara statistik.
Menurut Suarni Norawati (2019) terdapat tujuh alat pengendalian kualitas untuk mengidentifikasikan dan menganalisis masalah kualitas yaitu lembar periksa, diagram sebar, diagram sebab-akibat, diagram pareto, diagram alir dan peta kendali. Tetapi pada penelitian ini hanya menggunakan lima sebagai berikut:

1. Lembar Periksa (Check Sheet)

Alat pengendalian kualitas, yang digunakan untuk mengumpulkan data yang akan disajikan dalam bentuk tabel (Fakhri \& Kamal, 2010).

2. Histogram

Menurut Esty (2013) histogram adalah alat pengendalian mutu untuk menunjukkan variasi data dan disusun dalam bentuk bar.

3. Diagram Pareto

Menurut Esty (2013) diagram pareto adalah alat pengendalian kualitas untuk membandingkan berbagai kejadian yang akan membantu memutuskan prioritas penanganan.

4. Diagram Sebab Akibat

Diagram yang digunakan untuk menggambarkan hubungan antara 
karakteristik mutu dan faktor penyebabnya (Sulaeman, 2014).

5. Peta Kendali/ Control Chart Menurut Harahap (2016) peta kendali adalah alat untuk mengawasi suatu proses yang sedang berjalan dan membantu mendeteksi penyimpangan yang terjadi. Penelitian ini menggunakan jenis I-MR Chart dengan rumus sebagai berikut: (Nuroktavany \& Wachidah, 2004).

$$
\overline{\mathrm{X}}=\frac{X i}{n} ; \overline{\mathrm{MR}}=\frac{M R i}{n}
$$

Peta Kendali MR Peta Kendali X

$$
\begin{array}{ll}
\mathrm{GT}=\overline{\mathrm{MR}} & \mathrm{GT}=\overline{\mathrm{X}} \\
\mathrm{UCL}=\mathrm{D}_{4} \overline{\mathrm{MR}} & \mathrm{UCL}=\overline{\mathrm{X}}+3 \frac{\overline{\mathrm{MR}}}{1,128} \\
\mathrm{LCL}=\mathrm{D}_{3} \overline{\mathrm{MR}} & \mathrm{LCL}=\overline{\mathrm{X}}-3 \frac{\overline{\mathrm{MR}}}{1,128}
\end{array}
$$

\section{HASIL DAN PEMBAHASAN}

\section{Proses Produksi Bayam Jepang}

\section{Tahap Budidaya}

a. Pembibitan

Proses pembibitan di PO. Sayur Organik Merbabu membutuhkan waktu kurang lebih 30 hari. Proses dimulai dari pencampuran kompos dan tanah sebanyak 1:1 yang diayak. Hasil ayakan dimasukkan ke dalam polybag dan setelah itu benih dimasukkan satu per satu. Untuk perawatan benih dilakukan penyiraman dan penyemprotan Plant Growth Promoting Rhizobacteria atau PGPR yang bertujuan untuk mencegah penyakit selama proses pembibitan.

b. Pengolahan Lahan

Pertama, lahan diolah dan dicangkul terlebih dahulu untuk menggemburkan tanah. Setelah itu dibuat bedengan dengan ketinggian 20 $\mathrm{cm}$ dengan panjang menyesuaikan dengan lahan yang akan diolah. Pemberian pupuk dasar yang terdiri dari pupuk kandang yang telah difermentasi. Kemudian dilakukan pemberian mikrooorganisme lokal, agensi hayati seperti Beauveria dan Trichoderma untuk mencegah hama penyakit pada tanaman Bayam Jepang. Terakhir adalah pemberian kapur dolomit, pemasangan mulsa dan penutupan dengan tanah.

c. Penanaman

Penanaman dilakukan pada bibit yang sudah berumur 30 hari dan dengan jarak tanam 20x20 cm. 


\section{d. Perawatan}

Proses perawatan dimulai sejak tanaman berumur 7 hari. Perawatan awal adalah penyulaman untuk tanaman yang mati. Setelah itu dilakukan penyiangan setelah tanaman berumur 7 hari. Pada umur 14 hari dilakukan pemupukan susulan pupuk organik cair hasil fermentasi urin kelinci dengan konsentrasi $100 \mathrm{ml}$ per 10 liter air.

e. Pengendalian Hama dan Penyakit Hama yang menyerang Bayam Jepang adalah ulat grayak, ulat tanah, uret, orong-orong, kutu daun dan gangsir. Sedangkan penyakit yang menyerang adalah busuk pangkal batang, daun kuning dan jamur milzu. Pencegahan yang dilakukan untuk mengatasi hama adalah metasium dan Beauveria yang diaplikasikan di tanah. Sedangkan pengendalian yang dilakukan terhadap tanaman yang sudah terserang hama adalah pestisida nabati hasil dari ekstrak daun suren dan pengendalian secara teknis budidaya yaitu dengan melakukan penanaman di dalam greenhouse.

\section{f. Pemanenan}

Pemanenan dilakukan pada pagi atau sore hari dengan syarat tanaman sudah berumur 30 hari, memiliki panjang $30 \mathrm{~cm}$ dan bobot sekitar 100 gram.

\section{Pascapanen}

a. Sortasi

Proses pengambilan daun yang rusak, yang terkena hama dan penyakit seperti busuk dan daun kuning.

\section{b. $\quad$ Grading}

Proses pemisahan Bayam Jepang dilakukan berdasarkan grade yang sudah ditetapkan sebagai berikut:

i. Grade I, tanaman dengan panjang sekitar $30 \mathrm{~cm}$, bobot $100 \mathrm{~g}$ dan dalam kondisi kering. Kondisi fisik yang diharapkan adalah daun tidak menguning dan tidak bolting.

ii. Grade II, tanaman dengan panjang kurang dari $30 \mathrm{~cm}$ atau lebih dari $40 \mathrm{~cm}$, bobot kurang dari 100 gram dan lebih dari 300 gram dengan kondisi fisik tidak bolting dan sisa serangan hama tidak terlalu parah. 
iii. Grade III, tanaman yang sudah bolting dan busuk, terkena serangan hama yang parah.

c. Pengemasan

Jenis pengemasan yang diterapkan berbeda, ditentukan berdasarkan lokasi konsumen dan tempat pengiriman. Pengiriman ke daerah Surabaya menggunakan kertas koran yang dibalutkan ke tanaman dan disusun ke dalam kardus. Daerah Joglosemar menggunakan plastik curah dan plastik pack dan disusun ke dalam kardus dan untuk di luar pulau seperti Kalimantan, dilakukan pengemasan pack dahulu setelah itu disusun rapi di dalam kardus.

\section{Pengidentifikasian Masalah Dalam Pengendalian Mutu Bayam Jepang}

\section{a. Lembar Periksa}

Lembar periksa adalah alat yang digunakan untuk mengumpulkan dan menganalisis data dalam bentuk tabel, berisi jumlah produksi dan jenis ketidaksesuain yang disertai dengan jumlah dari cacat yang ditemukan, yang bertujuan untuk mempermudah proses pengumpulan dan analisis data (Fakhri dan Kamal, 2010)

Pada penelitian ini pengisian lembar periksa dilakukan pada saat bayam jepang telah dipanen dan dibawa ke ruang sortasi untuk dipisahkan batang atau daun yang tidak masuk standar kualitas. Lembar periksa menunjukkan bahwa terdapat lima jenis cacat yaitu daun cacat sebanyak $8835 \mathrm{~g}$, batang patah $7760 \mathrm{~g}$, daun kuning 2203 g, tanaman kerdil 1781 g dan busuk sebanyak 1658 g. Total kerusakan secara keseluruhan adalah $22237 \mathrm{~g}$ dengan rata rata persentase kerusakan mencapai 2,4 \% dari total produksi sebesar $907500 \mathrm{~g}$.

\section{b. Diagram Histogram}

Histogram jenis cacat Bayam Jepang adalah sebagai berikut:

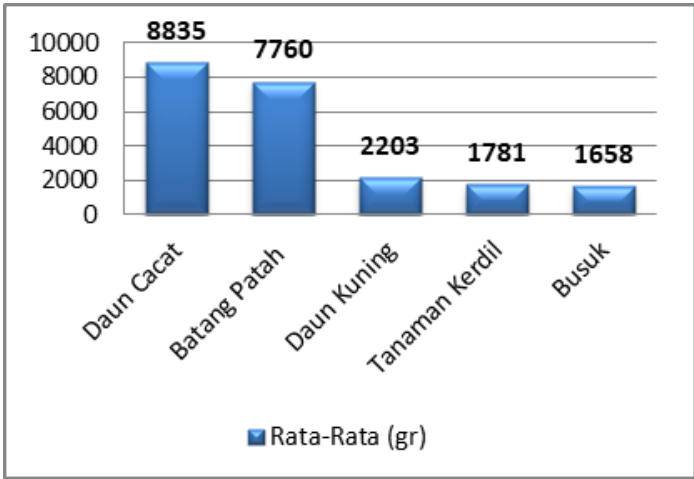

Gambar 1. Histogram Produk Cacat Bayam Jepang 
Menurut Esty (2013) Histogram adalah alat yang digunakan untuk menunjukkan variasi data pengukuran, seperti berat badan, temperatur, dan sebagainya. Histogram berbentuk bar yang menunjukkan distribusi frekuensi dari suatu faktor dan menunjukkan variasi dari setiap proses.

Gambar 1 menunjukkan bahwa jenis cacat yang paling banyak terjadi adalah daun cacat yaitu sebesar 8835 g. Semakin besar tingkat kerusakan yang didapatkan akan menyebabkan kerugian terhadap perusahaan, sehingga perlu dilakukan pemecahan masalah dan mencari tahu penyebab cacat tersebut. Hasil pengamatan daun cacat terjadi karena serangan hama dan penyakit, sehingga pihak perusahaan perlu melakukan pengendalian hama dan penyakit menggunakan PGPR dan agensi hayati.

\section{c. Peta Kendali (Control Chart)}

Menurut Harahap (2016) peta kendali merupakan alat grafik yang digunakan untuk mengawasi suatu proses yang sedang berjalan atau dilakukan. Pada penelitian ini peta kendali yang digunakan adalah I-MR chart dengan tujuan mencari apakah dari setiap produksi terdapat kendala yang melewati batas kendali atau batas kendali bawah. Adapun peta kendali yang sudah diolah adalah sebagai berikut:

\section{Daun cacat}

Daun cacat merupakan jenis cacat dengan tingkat kerusakan yang paling tinggi. Gambar 2 berikut ini adalah peta kendali untuk daun cacat. 


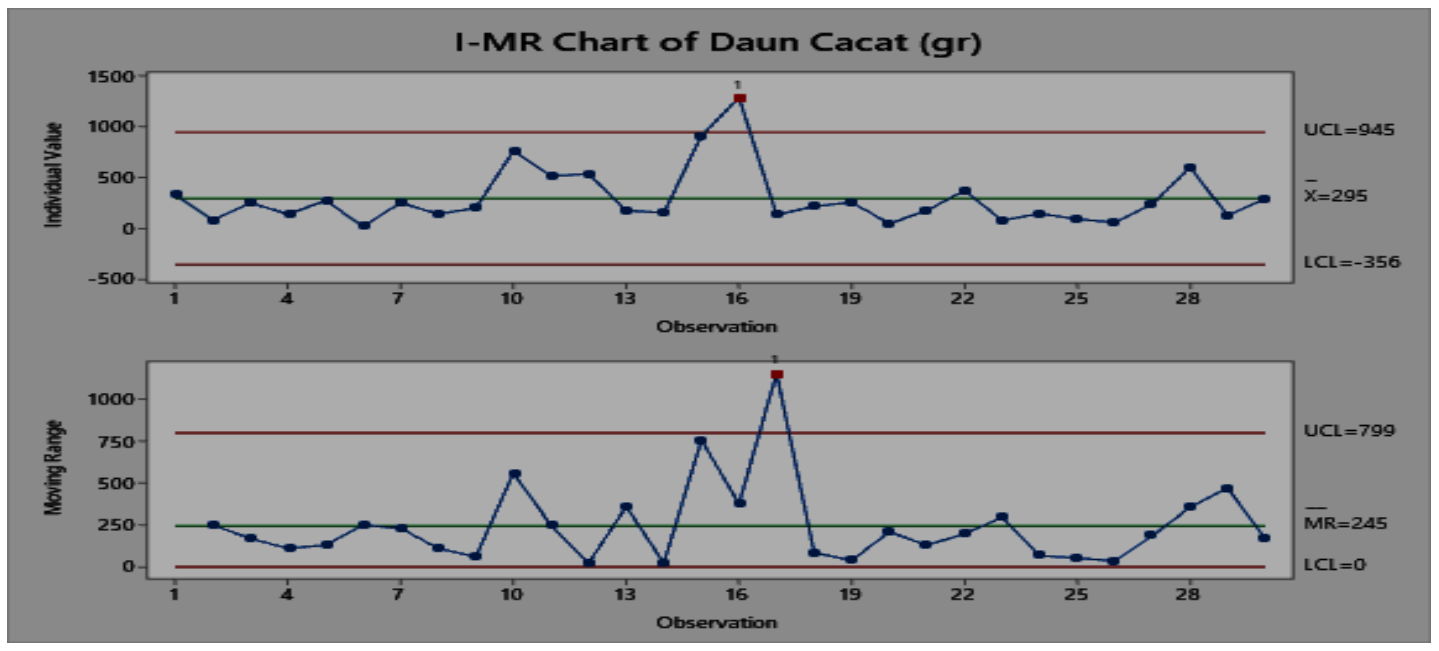

Gambar 2. Peta I-MR Chart untuk Daun Cacat

Berdasarkan peta kendali pada Gambar 2 didapatkan nilai UCL sebesar 799, $\overline{\mathrm{MR}}$ sebesar 245 dan nilai LCL sebesar 0 untuk peta kendali moving range. Sedangkan peta kendali individual didapatkan nilai UCL sebesar 945, nilai $\overline{\mathrm{X}}$ sebesar 295 dan nilai LCL sebesar -356. Gambar 2 juga menunjukkan terdapat 1 proses melewati UCL yaitu titik ke-16 pada tanggal 04 Februari dengan tingkat kerusakan sebesar 1186 g dari produksi 48 kg. Berdasarkan pengamatan, kerusakan ini disebabkan oleh hama dan penyakit, sehingga perlu dilakukan pengendalian lebih baik lagi terhadap hama dan penyakit seperti penggunaan pestisida nabati.

2. Batang Patah

Batang patah adalah jenis cacat tertinggi kedua yang ditemukan selama proses produksi Bayam Jepang. Gambar 3 berikut adalah peta kendali untuk jenis cacat batang patah. 


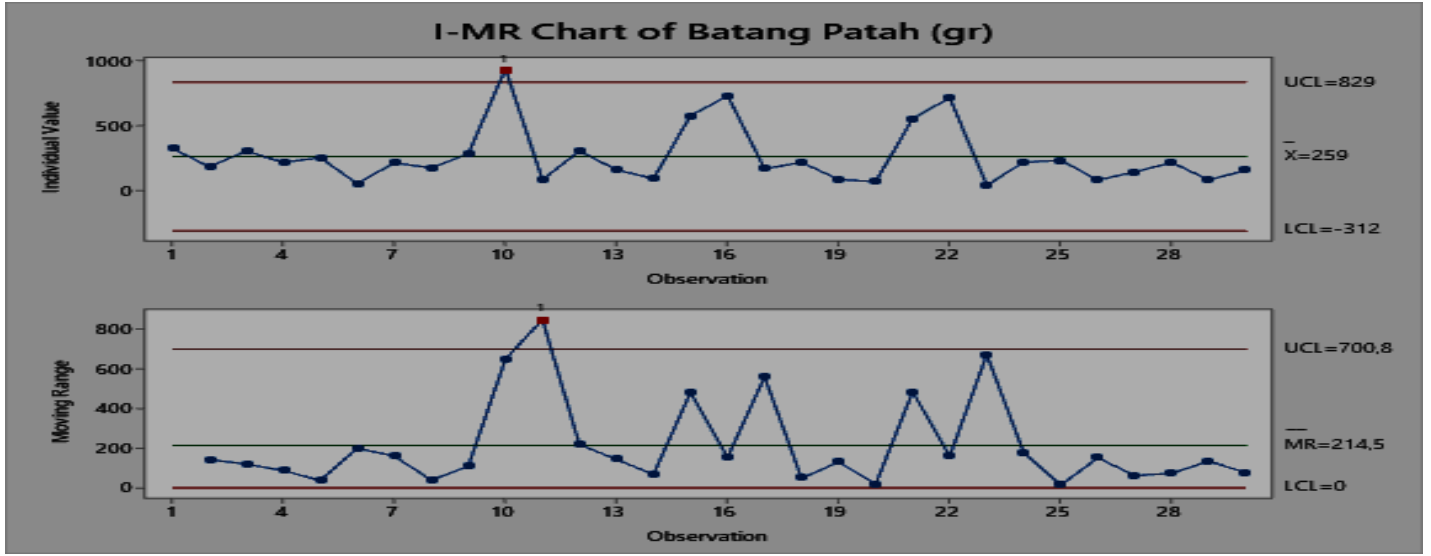

Gambar 3. Peta I-MR Chart untuk Batang Patah

Nilai UCL yaitu 829, $\overline{\mathrm{X}}$ yaitu 259 dan LCL yaitu -312 untuk peta kendali individual. Sedangkan untuk moving range nilai UCL yaitu $700,8, \overline{\mathrm{MR}}$ yaitu 214,4 dan nilai LCL yaitu 0 dan terdapat satu proses yang melewati UCL yaitu pada titik ke-10 pada 28 Januari 2020 dengan tingkat kerusakan sebesar $930 \mathrm{~g}$ dari jumlah produksi sebesar 41,5 kg. Batang patah bisa terjadi oleh beberapa hal yaitu penyusunan yang salah dan kurang ketelitian, sehingga tenaga kerja dituntut lebih hati-hati dan teliti dalam memproses Bayam Jepang.

3. Daun Kuning

Daun kuning adalah jenis cacat yang ditemukan selama proses produksi bayam jepang di PO. Sayur Organik Merbabu. Grafik kendali untuk daun kuning terdapat pada Gambar 4.

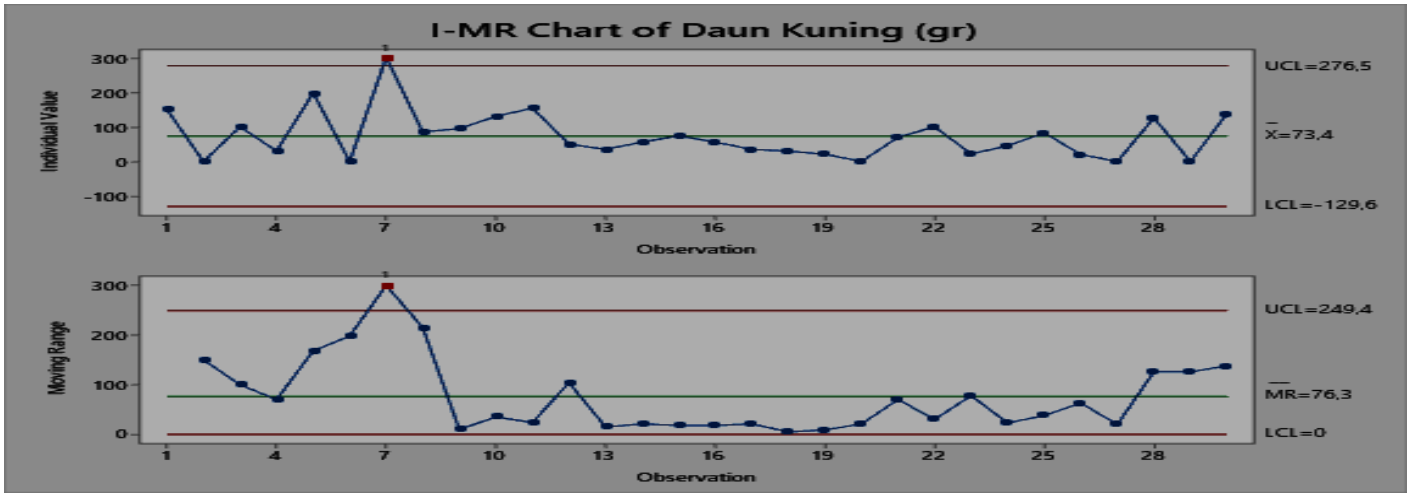

Gambar 4. Peta I-MR Chart untuk Daun Kuning 
Nilai UCL adalah 276,5, nilai $\overline{\mathrm{X}}$ 73,4, nilai LCL 129,6 dari peta individual dan nilai peta kendali moving range nilai UCL sebesar 249,4, nilai $\overline{\mathrm{MR}}$ sebesar 76,3 dan nilai LCL sebesar 0. Gambar 4 juga menunjukkan adanya satu titik yang melewati batas kendali atas yaitu pada titik ke 7 pada tanggal 23 Januari 2020 dengan kuantitas tingkat cacat sebanyak $300 \mathrm{~g}$ untuk jumlah produksi 68 kg. Daun yang kuning bisa disebabkan oleh tanaman yang kekurangan air dan serangan hama dan penyakit, sehingga perlu dilakukan perawatan lebih rutin dan melakukan jadwal penyiraman lebih baik lagi untuk menekan kerusakan akibat daun kuning.

\section{Tanaman Kerdil}

Tanaman kerdil adalah jenis cacat yang ditemukan selama proses produksi Bayam Jepang. Kendali jenis cacat tersebut pada Gambar 5.

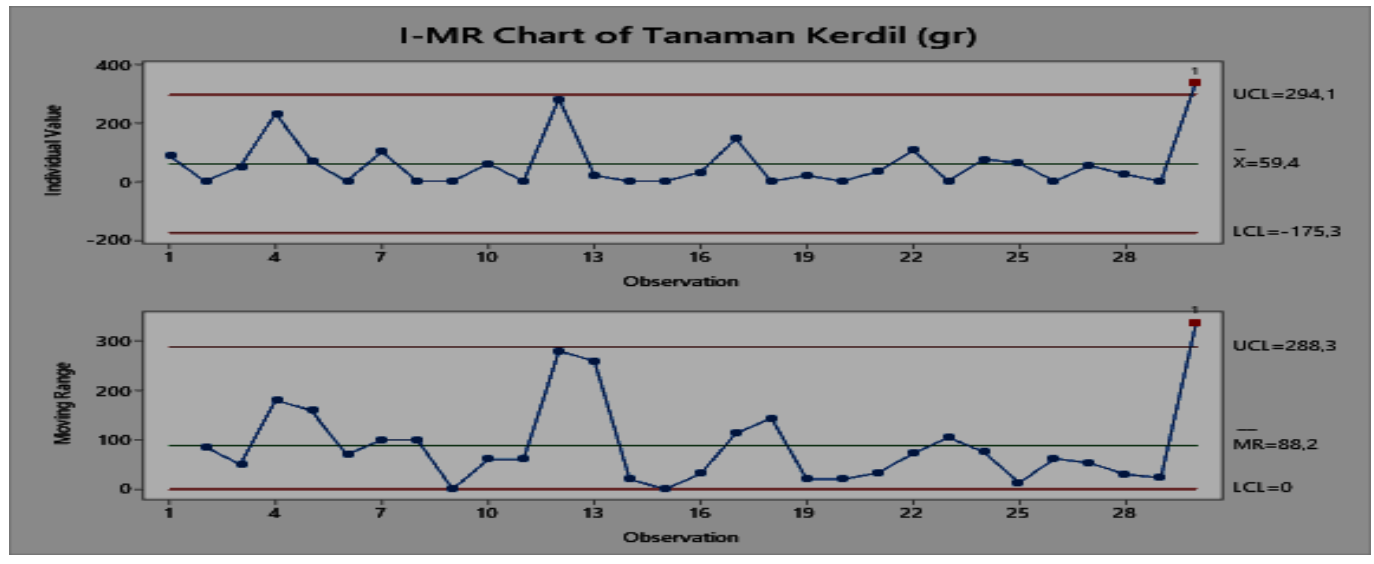

Gambar 5. Peta I-MR Chart untuk Tanaman Kerdil

Nilai UCL yang didapatkan yaitu 294,1, Xbar sebesar 59,4 dan nilai LCL sebesar -175,3 dari peta kendali individual. Sedangkan untuk peta kendali moving range nilai UCL yang didapatkan yaitu 288,3, nilai MR sebesar 88,2 dan nilai LCL yaitu 0 dan terdapat satu titik yang melewati batas kendali atas yaitu pada titik ke 30 pada tanggal 20 Februari 2020 dengan kuantitas cacat sebesar 339 g dengan jumlah produksi $60 \mathrm{~kg}$. Hal tersebut 
terjadi karena tanaman yang subur menutupi tanaman tersebut dan menghambat pertumbuhan yang lain, sehingga perlu dilakukan pelebaran jarak tanam untuk menghindari pengumpukan daun yang dapat menghambat pertumbuhan tanaman lainnya.

\section{Busuk}

Busuk adalah jenis cacat terakhir yang ditemukan selama proses produksi Bayam Jepang, adapun grafik kendali untuk cacat busuk pada gambar 6.

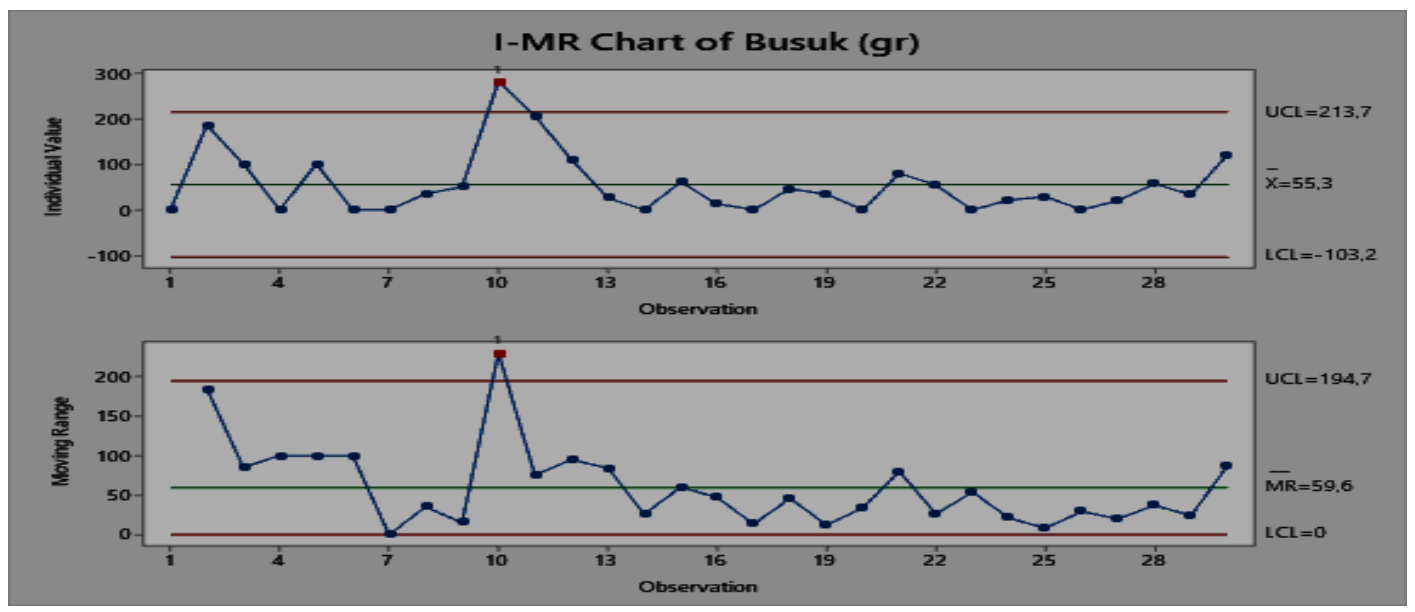

Gambar 6. Peta I-MR Chart untuk Cacat Busuk

Adapun nilai dari UCL yaitu 213,7, $\overline{\mathrm{x}}$ yaitu 55,3 dan LCL yaitu 103,2 untuk peta kendali individual. Sedangkan untuk peta kendali moving range untuk nilai UCL yaitu 194,7 , MR sebesar 59,6 dan nilai LCL yaitu 0 dan terdapat satu titik yang melewati batas kendali atas yaitu pada titik 10 pada tanggal 28 Januari 2020 dengan kuantitas busuk sebanyak 240 g dengan jumlah produksi sebanyak 41,5 kg. Tanaman busuk biasanya terjadi karena tingkat kelembaban yang berlebih pada lingkungan ataupun tempat budidaya, sehingga perlu dilakukan drainase di sekitar daerah budidaya pada saat musim penghujan untuk menghindari kelembaban berlebih.

\section{d. Diagram Pareto}

Pareto adalah salah satu diagram yang digunakan untuk 
membandingkan berbagai kategori kejadian yang disusun menurut ukuran yang paling besar diletakkan di sebelah kiri dan yang paling kecil di sebelah kanan. Kegunaan dari penggunaan pareto yaitu membantu untuk memutuskan perhatian pada persoalan utama yang harus ditangani dalam upaya perbaikan. Jenis cacat yang paling banyak terjadi ditunjukkan oleh batang grafik yang tertinggi yang diposisikan di paling kiri dan tingkat cacat yang paling rendah di bagian kanan (Esty, 2013). Adapun hasil dari pembuatan diagram pareto adalah sebagai berikut:

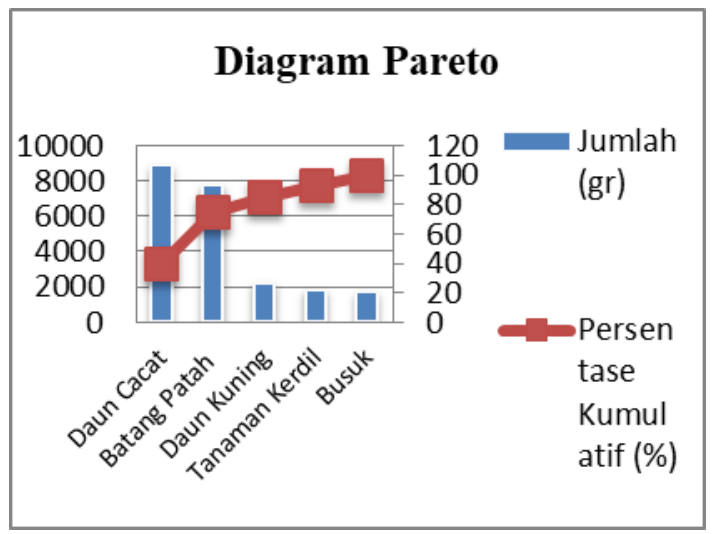

Gambar 7. Diagram Pareto Jenis Cacat Bayam Jepang

Berdasarkan gambar 7 dapat
dilihat bahwa permasalahan yang
membutuhkan prioritas perbaikan

utama adalah daun cacat dengan kategori kerusakan terdiri dari serangan hama dan remuk, sehingga perlu dilakukan penanganan lebih lanjut seperti pencegahan, perawatan dan melakukan pengawasan terhadap tenaga kerja agar tidak terjadi kerusakan pada daun Bayam Jepang.

\section{Faktor-Faktor Yang Mempengaruhi Kualitas Bayam Jepang}

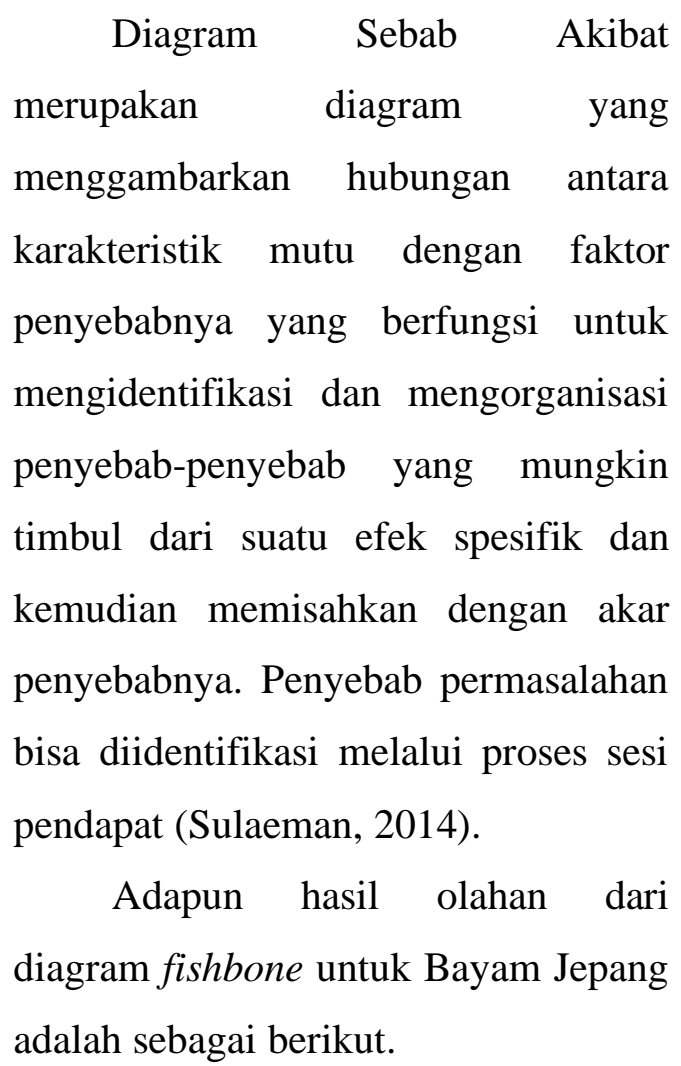

Diagram Sebab Akibat 


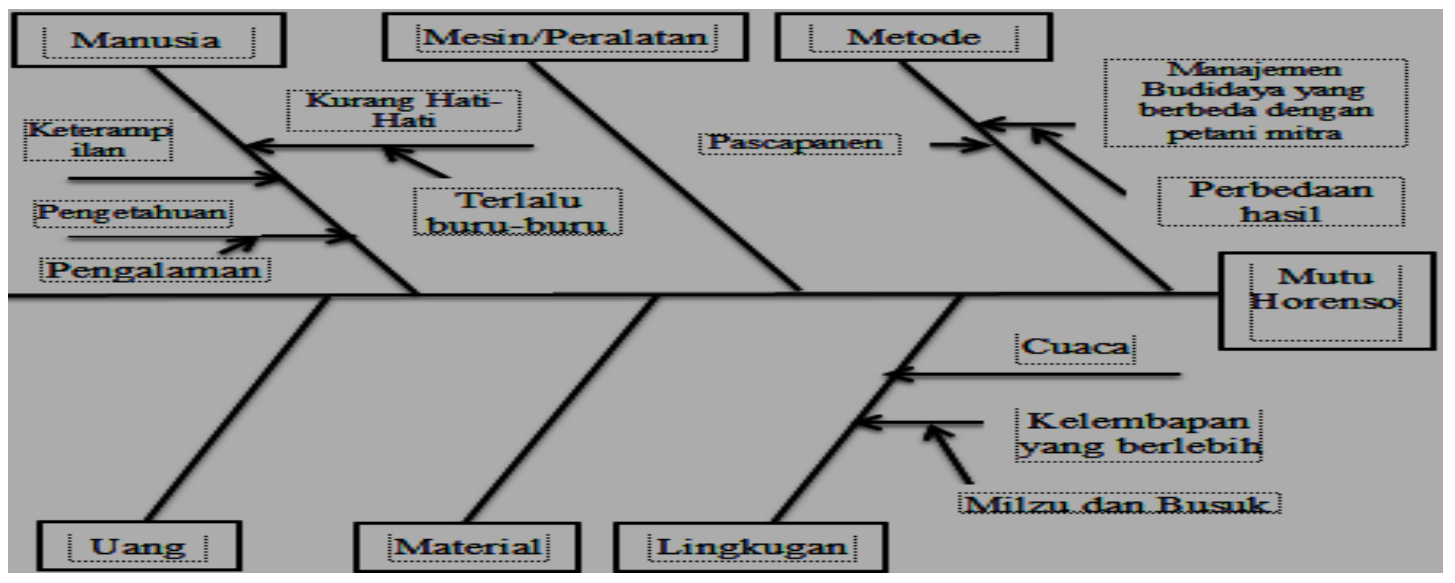

Gambar 8. Diagram Fishbone Bayam Jepang

Berdasarkan hasil wawancara mendalam yang dilakukan dengan metode trianggulasi, dengan bantuan pedoman wawancara dengan key informant dan informan didapatkan hasil bahwa faktor-faktor yang mempengaruhi kualitas bayam jepang adalah faktor manusia,metode dan juga lingkungan. Sedangkan menurut key informnat dan informan faktor material, mesin dan uang tidak mempengaruhi kualitas bayam jepang.

\section{Faktor Manusia}

Kasus PO. Sayur Organik Merbabu yaitu sumber daya manusia yang kurang paham seperti mahasiswa atau siswa PKL sehingga dalam segi keterampilan belum memenuhi dalam memproses Bayam Jepang secara baik.
Selain keterampilan, karyawan juga harus mengerti atau memiliki pengetahuan tentang Bayam Jepang, sehingga lebih hati-hati dalam proses produksi agar tidak terjadi kesalahan. Tindakan pengendalian mutu yang perlu dilakukan adalah memantau dan memberi sosialisasi Bayam Jepang kepada mahasiswa maupun karyawan

\section{Faktor Metode}

PO. Sayur Organik Merbabu merupakan perusahaan yang bermitra dengan kelompok Tani Citra Muda. Sistem yang dilakukan adalah membagikan alokasi penanaman yang akan dibudidaya dengan manajemen masing-masing petani. Hal ini berpeluang menghasilkan kualitas Bayam Jepang yang berbeda. Selain 
hal tersebut hal yang dapat mempengaruhi adalah pemanenan yang terlambat berdampak terhadap kualitas Bayam Jepang.

Dari masalah tersebut perlu
dilakukan sosialisasi rutin untuk
mengedukasi mengenai standar
kualitas yang ditetapkan oleh
perusahaan dan juga melakukan
perencanaan secara lebih baik lagi
untuk menekan keterlambatan panen.

\section{Faktor Lingkungan}

Saat dilakukan penelitian Indonesia sedang memasuki musim penghujan. Selama penelitian dan pengumpulan jenis cacat, banyak ditemukan serangan hama dan penyakit. Salah satu faktor penyebabnya adalah perubahan cuaca dan tingkat kelembapan yang tinggi di dalam greenhouse. Hal yang dapat dilakukan untuk menekan permasalahan ini adalah pemberian pestisida nabati untuk menghentikan penyebaran hama dan penyakit.

\section{KESIMPULAN DAN SARAN}

\section{Kesimpulan}

Terdapat lima jenis cacat Bayam Jepang yang terdiri dari daun cacat, batang patah, daun kuning, tanaman kerdil dan busuk dari hasil pengamatan selama 30 hari produksi dengan tingkat cacat paling tinggi yaitu kategori daun cacat mencapai $8835 \mathrm{~g}$. Hasil pengolahan diagram fishbone didapatkan bahwa faktor-faktor yang mempengaruhi kualitas bayam jepang adalah faktor manusia, metode dan lingkungan.

\section{Saran}

Perlu dilakukan pencegahan dan perawatan serta pengawasan yang lebih ketat terhadap tenaga kerja. Selain itu untuk meningkatkan kualitas perlu dilakukan sosialisasi terhadap petani dan tenaga kerja terkait kualitas Bayam Jepang akan diproduksi agar menekan cacat pada Bayam Jepang.

\section{DAFTAR PUSTAKA}

Dermiyati. 2015. Sistem Pertanian Organik Berkelanjutan SNI 6759:2016. BSNI: Jakarta.

Ekaningtias, D. 2011. Analisis 
Pendapatan Dan Efisiensi Teknis Usahatani Bayam Jepang (Horenso ) Kelompok Tani Agro Segar Kecamatan Pacet Kabupaten Cianjur Jawa Barat. Skripsi. Institut Pertanian Bogor.

Esty, G. A. 2013. Analisis pengendalian kualitas benih melon (Cucumis melo L.) di CV. MULTI GLOBAL AGRINDO (MGA) Kabupaten karanganyar. Skripsi. Universitas Sebelas Maret Surakarta.

Fakhri, F. A., \& Kamal, M. 2010. Analisis Pengendalian Kualitas Produksi di PT. Masscom Graphy dalam Upaya Mengendalikan Tingkat Kerusakan Produk Menggunakan Alat Bantu Statistik. Skripsi. Fakultas Ekonomi Universitas Diponegoro Semarang.

Harahap, S. A. 2016. Analisis Pengendalian Kualitas Produk Keripik Pisang Puri Jaya pada PD. Puri Jaya di Bandar Lampung. Jurnal Ekonomi dan Bisnis. 2(1): 1-33.

Nugrahani, F. 2014. Metode Penelitian Kualitatif. Penelitian Pendidikan Bahasa. Surakarta.

Nuroktavany, S. E., \& Wachidah, L. 2004. Implementasi Diagram Kendali Kombinasi Individual (X) dan Moving Range (MR) pada Komponen Pesawat.
Prosiding Statistika. 3(1): 35-42.

Ratnadi, \& Suprianto, E. 2016. Pengendalian Kualitas Produksi Menggunakan Alat Bantu Statistik (Seven Tools) dalam Upaya Menekan Tingkat Kerusakan Produk. Jurnal Indept. 6(2):10-18.

Suarni Norawati, Z. 2019. Analisis Pengendalian Mutu Produk Roti Manis dengan Metode Statistical Process Control (SPC) Pada Kampar Bakery Bangkinang. Jurnal Menara Ekonomi. 5(2): 103-110.

Sugiono. 2009. Memahami Penelitian Kuantitatif. Bandung: Penerbit Alfabeth.

Sulaeman. 2014. Analisa Pengendalian Kualitas untuk Mengurangi Produk Cacat Speedometer Mobil dengan Menggunakan Metode Qcc Di PT.INS. Jurnal PASTI. VIII (1): 71-95.

Suyitno. 2018. Metode Penelitian Kualitatif, Konsep, Prinsip dan Operasionalnya. Tulungagung: Akedemia Pustaka.

Wirjohamidjojo, S., \& Swarinoto, Y. 2010. IKLIM KAWASAN INDONESIA (Dari Aspek Dinamik - Sinoptik). Jakarta: Badan Meteorologi Klimatologi dan Geofisika. 